\title{
Utilização de probiótico e de lactulose no controle de hiperamonemia causada por desvio vascular portossistêmico congênito em um cão
}

\author{
Use of probiotic and lactulose to control hyperammonemia secundary to a congenital portosystemic \\ shunt in a dog
}

\author{
Alexandre Martini de Brum ${ }^{\mathrm{I} *}$ Tatiana Champion ${ }^{\mathrm{I}}$ Rosana Zanatta ${ }^{\mathrm{I}}$ Mirela Tinucci Costa \\ Júlio Carlos Canola ${ }^{\mathrm{I}}$
}

\begin{abstract}
O desvio vascular portossistêmico pode ser congênito ou adquirido nos cães. A enfermidade pode levar a alterações neurológicas decorrentes de encefalopatia hepática e a hiperamonenia é um dos mecanismos implicados na fisiopatologia deste quadro. O tratamento clínico visa a reduzir os níveis séricos de amônia com o uso de antibióticos e lactulose. Em humanos com hepatopatias, os probióticos podem ser utilizados para reduzir a hiperamonemia. A resposta clínica e laboratorial de um cão com desvio vascular portossistêmico foi demonstrada com a utilização de lactulose e de probiótico, isoladamente e associados, sendo que a melhor evolução foi obtida na terapia conjunta.

Palavras-chave: cão, desvio vascular portossistêmico, hiperamonemia, probiótico, lactulose.
\end{abstract}

- NOTA -

\section{ABSTRACT}

The portosystemic shunt may be congenital or acquired in dogs. The disease can cause neurologic signs manifested by hepatic encephalopathy. The hyperammonemia is a mechanism involved on the physiopathology of this disorder. The objective of the clinical treatment is to decrease the levels of ammonia with antibiotics and lactulose. In human medicine, probiotics are used to reduce the hyperammonemia in patients with hepatic diseases. This report compares the use of lactulose and probiotic monotherapy and in association in a dog with congenital portosystemic shunt, showing the patient's clinical and laboratorial evolutions. The better clinical and laboratorial reponse was obtained with the association of lactulose and probiotic.

Key words: dog, portosystemic shunt, hyperammonemia, probiotic, lactulose
As anomalias vasculares portossistêmicas, conhecidas como desvios portossistêmicos, são comunicações vasculares anômalas entre a circulação portal e a circulação venosa sistêmica (JOHNSON, 2000). Essas comunicações podem ser congênitas ou adquiridas (LAMB \& WHITE, 1998; VULGAMOTT, 1979). Também podem ser classificadas como intra ou extra-hepáticas, sendo a intra-hepática decorrente da persistência de fluxo sangüíneo através do ducto venoso, mais comum nas raças de grande porte (LAMB \& WHITE, 1998). Raças "toys" apresentam a forma congênita extra-hepática com maior freqüência, porém também há relatos de desvios intra-hepáticos (HUNT et al., 2000).

O desvio vascular priva o fígado de substâncias hepatotróficas, resultando em atrofia e insuficiência do órgão (JOHNSON et al., 1987). Além disso, quando o sangue da veia porta passa diretamente para a circulação sistêmica sem sofrer detoxificação hepática, leva à encefalopatia hepática (JOHNSON, 2000). Diversas substâncias estão envolvidas em sua fisiopatologia, entre elas a amônia, os aminoácidos aromáticos, os ácidos graxos de cadeia curta, os mercaptanos, os benzodiazepínicos endógenos e o ácido $\gamma$-aminobutírico, provenientes do trato gastrintestinal (BUNCH, 2003). Exames laboratoriais de rotina podem sugerir disfunção hepática, mas nem sempre estão alterados; portanto, a dosagem de ácidos

${ }^{1}$ Departamento de Clínica e Cirurgia Veterinária, Faculdade de Ciências Agrárias e Veterinárias (FCAV), Universidade Estadual Paulista (UNESP). Av. Pedro Marques, 282, 14882-222 Jaboticabal,SP, Brasil. E-mail: alexmbrum@bol.com.br.*Autor para correspondência. 
biliares pré e pós-prandiais, a ultra-sonografia, a portografia ou a cintilografia são necessárias para o diagnóstico definitivo (JOHNSON, 2000). Achados ultra-sonográficos, como microhepatia e relação veia porta/aorta e veia porta/cava caudal menores que $1: 1$, são bastante sugestivos de desvios extra-hepáticos. Já as comunicações intra-hepáticas caracterizam-se pela presença de vasos anômalos e tortuosos dentro do parênquima, ligando os dois sistemas venosos (D'ANJOU et al., 2004).

O tratamento definitivo é cirúrgico, por meio da correção da anomalia vascular, porém alguns pacientes podem apresentar sinais neurológicos graves e de difícil controle, mesmo após a correção (YOOL \& KIRBY, 2002). A cirurgia é contra-indicada na presença de hipertensão portal (VULGAMOTT, 1979). O tratamento clínico é paliativo e visa ao controle da encefalopatia hepática e da insuficiência hepática (BUNCH, 2003). A terapia medicamentosa consiste de antibióticos (metronidazol ou neomicina) para reduzir a população bacteriana produtora de urease; de lactulose, que aumenta a eliminação do conteúdo intestinal e acidifica o lúmen intestinal, transformando a amônia em amônio; e da dieta hipoprotéica, que oferece menos substrato para a produção de amônia no intestino (BUNCH, 2003). O tratamento clínico é eficaz a curto prazo, porém a cirurgia traz melhores resultados a longo prazo (YOUMANS \& HUNT, 1998).

Os probióticos estão sendo utilizados para combater a hiperamonemia em pacientes humanos (LOGUERCIO et al., 1995). Bactérias, como Bifidobacterium bifidum e Streptococcus faecium, diminuem competitivamente a microbiota produtora de urease, reduzindo a absorção de amônia (LOGUERCIO et al., 1987). A lactulose, por sua vez, é considerada um prebiótico, pois aumenta a capacidade lactofermentativa de populações de Lactobacillus. A utilização de prebióticos, como a lactulose e os frutooligossacarídeos, tem ação sinérgica, pois estimula o crescimento das bactérias benéficas (SCHUMANN, 2002). O uso dos probióticos em pequenos animais ainda é restrito aos casos de gastrenterites. Este relato compara a utilização de lactulose e de probiótico, isoladamente e associados, em um cão com anomalia vascular portossistêmica congênita.

Foi atendido no Hospital Veterinário da Universidade Estadual Paulista (UNESP), Campus de Jaboticabal, SP, um cão da raça Maltês, macho, com $2,3 \mathrm{~kg}$ e 10 meses de idade, apresentando queixa de prostração intensa, principalmente após a alimentação, e sinais de encefalopatia hepática (andar em círculo compulsivo, sialorréia e amaurose). Ao exame físico, observaram-se hipotermia $\left(37,0^{\circ} \mathrm{C}\right)$, desidratação leve e estado mental deprimido, o que impediu a realização de um exame neurológico completo. Foi coletado sangue para realização de exames complementares (Tabela 1). O cão recebeu fluidoterapia com solução de $\mathrm{NaCl}$ 0,9\% e glicose $5 \%$. Com base no histórico, no exame físico e nas alterações laboratoriais, suspeitou-se de desvio portossistêmico. Assim que o animal retornou ao nível de consciência normal, iniciou-se antibioticoterapia por via oral com metronidazol (7,5 $\mathrm{mg} \mathrm{kg}^{-1}$ a cada 12 horas) e ampicilina sódica ( $22 \mathrm{mg} \mathrm{kg}^{-1}$ a cada 8 horas), lactulose ( $1 \mathrm{ml} \mathrm{a} \mathrm{cada}$ 8 horas, por via oral), dieta comercial hipoprotéica e mel.

Após dois dias de tratamento, apresentou melhora significativa, sendo realizada a dosagem de ácidos biliares. Os valores foram: pré-prandial de 80 $\mu \mathrm{mol} \mathrm{L}-1(0-13 \mu \mathrm{mol} \mathrm{L}-1)$ e pós-prandial de $213 \mu \mathrm{mol} \mathrm{L}^{-1}$ $\left(0-30 \mu \mathrm{mol} \mathrm{L}^{-1}\right)$, compatíveis com a suspeita de anomalia vascular portossistêmica. No exame ultra-sonográfico, o cão apresentava microhepatia e vasos intra-hepáticos com calibre aumentado. A ligação anormal entre veia porta e veia cava caudal foi identificada, em plano sagital, no lobo hepático esquerdo. A terapia medicamentosa foi mantida, pois o proprietário não autorizou o procedimento cirúrgico.

Após 21 dias, suspenderam-se os antibióticos, mantendo apenas a dieta e a lactulose. Com duas semanas de tratamento, os exames laboratoriais foram repetidos (Tabela 1) e foi realizada dosagem de amônia sérica, que apresentou o valor de $478,6 \mu \mathrm{mol} \mathrm{L}^{-1}\left(14,67-54,00 \mu \mathrm{mol} \mathrm{L}^{-1}\right)$. Suspendeu-se a lactulose e foi iniciada terapia com probiótico composto de Bifidabacterium bifidum, Lactobacillus acidophilus, Lactobacillus plantarum, Streptococcus faecium e Saccharomyces cerevisiae (Florafort $^{\circledR}$ Vitafort), $2 \mathrm{~g}$ ao dia, por via oral, e a dieta hipoprotéica foi mantida. Com 15 dias de tratamento, o animal apresentava-se deprimido e a amônia com valor de $562,70 \mu \mathrm{ol} \mathrm{L}{ }^{-1}$. A lactulose foi introduzida e manteve-se o probiótico. $\mathrm{O}$ animal apresentou melhora clínica e a amônia sérica, após sete e 15 dias, apresentava os valores de 362,30 e $84,00 \mu \mathrm{ol} \mathrm{L}{ }^{-1}$, respectivamente. Com

Tabela 1 - Avaliação laboratorial de um cão com desvio vascular portossistêmico congênito durante o tratamento com lactulose e probiótico.

\begin{tabular}{lclll}
\hline Exames laboratoriais & Dia 0 & Dia 35 & Dia 120 & $\begin{array}{l}\text { Valores de } \\
\text { referência }\end{array}$ \\
\hline Leucócitos totais $\left(\mathrm{x} \mathrm{10}^{3} \mathrm{\mu l}^{-1}\right)$ & 23 & 27 & 20 & $6-18$ \\
Glicemia $\left(\mathrm{mg} \mathrm{dl}^{-1}\right)$ & 37 & 70 & --- & $65-118$ \\
Proteínas totais $\left(\mathrm{g} \mathrm{dl}^{-1}\right)$ & 4,2 & 5,5 & 6,7 & $5,8-7,9$ \\
Albumina $\left(\mathrm{g} \mathrm{dl}^{-1}\right)$ & 1,7 & 2,3 & 2,1 & $2,6-4,0$ \\
ALT $\left(\mathrm{U} \mathrm{l}^{-1}\right)$ & 181,5 & 105,5 & 46,4 & $10-88$ \\
\hline
\end{tabular}


dois meses de acompanhamento, a terapia com probiótico foi suspensa, pois o cão apresentava-se bem, sem recidiva das alterações neurológicas. Após dois anos de acompanhamento, o cão apresentava-se bem clinicamente.

A lactulose, juntamente com a dieta hipoprotéica, conforme recomendado por BUNCH (2003); JOHNSON (2000), levaram a uma evolução clínica satisfatória e à remissão do quadro clínico; todavia, a amônia sérica permanecia elevada. A utilização do probiótico isoladamente e da dieta não apresentou benefícios, pois o animal voltou a apresentar sintomatologia clínica e elevada amônia sérica, ao contrário do que LOGUERCIO et al. (1987) relataram em humanos com alterações hepáticas.

O controle da hiperamonemia mostrou-se mais eficiente quando foram associados a lactulose e o probiótico. A redução da amônia sérica provavelmente deve-se ao efeito sinérgico da diminuição da população bacteriana produtora de urease, pela competição com as bactérias do probiótico, pela capacidade da lactulose em inibir a formação de amônia, de reter o amônio (através da acidificação do lúmen intestinal) e pelo aumento da excreção do conteúdo intestinal, causada pela diarréia osmótica (BUNCH, 2003). Por essa razão, optou-se pelo uso diário de probiótico assegurando, dessa forma, que a flora intestinal esteja sempre povoada pelos microrganismos desejados. Nesse caso, a lactulose, utilizada como prebiótico, pode ter auxiliado na terapia probiótica (SCHUMANN, 2002). Possivelmente devido a esses dois fatores, a melhor resposta clínica do controle da encefalopatia hepática tenha sido conseguida com a associação da lactulose e probiótico. Apesar de a terapia cirúrgica apresentar um melhor resultado a longo prazo (YOUMANS \& HUNT, 1998), neste caso a resposta da terapia dietética e medicamentosa foi considerada satisfatória, pois houve redução da concentração de amônia sérica e os valores de albumina não apresentaram redução após a restrição protéica.

$\mathrm{O}$ uso isolado de probiótico não mostrou ser uma terapia útil. Observação semelhante ocorreu com o uso isolado da lactulose, uma vez que a amônia permaneceu elevada. A terapia conjunta foi eficiente, sendo uma opção nos casos em que a antibioticoterapia crônica queira ser evitada. Após um ano de tratamento, o animal não apresentava nenhuma reação adversa à terapia; todavia, a continuidade das avaliações clínicolaboratoriais é necessária para comprovar a eficácia e a segurança deste tratamento.

\section{AGRADECIMENTOS}

À Vitafort (Ribeirão Preto -SP), pela a doação da medicação utilizada no presente caso (probiótico - Florafort ${ }^{\circledR}$ ).

\section{REFERÊNCIAS}

BUNCH, S.E. Hepatobiliary disease in the dog. In: NELSON, R.W.; COUTO, C.G. Small animal internal medicine. 3.ed. St. Louis: Mosby, 2003. Cap.38, p.525-545.

D'ANJOU, M.A. et al. Ultrasonographic diagnosis of portosystemic shunting in $\operatorname{dog} s$ and cats. Vet Radiol Ultrasound, v.45, n.5, p.424-437, 2004.

HUNT, G.B. et al. Congenital portosystemic shunt in toy and miniature poodles. Aust Vet J, v.78, n.8, p.530-532, 2000.

JOHNSON, S.E. Chronic hepatic disorders. In: ETTINGER, S.J.; FELDMAN, E.C. Textbook of veterinary internal medicine 5.ed. Philadelphia: Saunders, 2000. Cap.143, p.1298-1325.

JOHNSON, C.A. et al. Congenital portosystemic shunts in dogs: 46 cases (1979-1986). J Am Vet Med Assoc, v.191, n.11, p.1478-1483, 1987.

LAMB, C.R.; WHITE, R.N. Morphology of congenital intrahepatic portacaval shunts in dogs and cats. Vet Rec, v.17, p.55-59, 1998 .

LOGUERCIO, C. et al. Enterococcus lactic acid bacteria strain SF 68 and lactulose in hepatic encephalopathy: a controled study. J Int Med Res, v.15, n.6, p.335-343, 1987.

LOGUERCIO, C. et al. Long term effects of Enterococcus faecium SF 68 versus lactulose in the treatment of pacients with cirrhosis and grade I-II hepatic encephalopathy. J Hepat, v.23, n.1, p.39-46, 1995.

SCHUMANN, C. Medical, nutritional and technological properties of lactulose. An update. Eur J Nutr, v.41, n.1, p.17-25, 2002.

VULGAMOTT, J.C. Hepatic encephalopathy associated with acquired portacaval shunt in a dog. J Am Vet Med Assoc, v.175, n.7, p.724-726, 1979. 